\title{
Corticosteroid or Nonsteroidal Antiinflammatory Drugs for the Treatment of Acute Gout: A Systematic Review of Randomized Controlled Trials
}

\author{
Christy Amanda Billy, Ricky Tanujaya Lim, Marinella Ruospo, Suetonia C. Palmer, \\ and Giovanni F.M. Strippoli
}

\begin{abstract}
Objective. Nonsteroidal antiinflammatory drugs (NSAID) are used as first-line agents to treat acute gout. Recent trials suggest a possible first-line role for corticosteroids.

Methods. We conducted a metaanalysis of randomized controlled trials (RCT) evaluating corticosteroid versus NSAID therapy (nonselective and selective) as treatment for acute gout. MEDLINE, EMBASE, and CENTRAL were systematically searched through August 2016. Outcomes included pain, bleeding, joint swelling, erythema, tenderness, activity limitation, response to therapy, quality of life, time to resolution, supplementary analgesics, and adverse events. Evidence quality was summarized using the GRADE (Grading of Recommendations Assessment, Development, and Evaluation) system.

Results. Six eligible trials (817 patients) were identified. The mean study followup was 15 days (range 4-30). Risks of bias were generally low. In low- to moderate-quality evidence, corticosteroids did not have different effects on pain score at $<7$ days [standardized mean difference (SMD) $-0.09,95 \%$ CI -0.26 to 0.08 ] or at $\geq 7$ days (SMD $0.32,95 \%$ CI -0.27 to 0.92 ) when compared with NSAID. There was no evidence of different risks of gastrointestinal bleeding [relative risk (RR) $0.09,95 \%$ CI 0.01-1.67]. There was no evidence of different responses to therapy on pain at $<7$ days (RR 1.07 , 95\% CI 0.80-1.44) and $\geq 7$ days, time to disease resolution, or number of supplementary analgesics used (MD 2.10 drugs, $95 \% \mathrm{CI}-1.01$ to 5.21). There was a lower risk of indigestion (RR $0.50,95 \%$ CI 0.27-0.92), nausea (RR 0.25, 95\% CI 0.11-0.54), and vomiting (RR 0.11, 95\% CI 0.02-0.56) with corticosteroid therapy.

Conclusion. There is no evidence that corticosteroids and NSAID have different efficacy in managing pain in acute gout, but corticosteroids appear to have a more favorable safety profile for selected adverse events analyzed in existing RCT. (First Release August 1 2017; J Rheumatol 2018;45:128-36; doi:10.3899/jrheum.170137)
\end{abstract}

Key Indexing Terms:

GOUT STEROIDS NONSTEROIDALANTIINFLAMMATORY DRUGS ACUTE PAIN

Gout is the most common cause of inflammatory arthritis, with an increasing prevalence and incidence in the United Kingdom and United States ${ }^{1,2}$. Acute gout causes short-term disability, leading to 5 additional work absence days on average each year and increases medical care costs per person affected by US $\$ 3165$ annually ${ }^{3}$. Gout disability-adjusted life

From the University of Sydney, Sydney, Australia; Diaverum Medical Scientific Office and Diaverum Academy, Lund, Sweden; Amedeo Avogadro University of Eastern Piedmont, Novara; University of Bari, Bari, Italy; Department of Medicine, University of Otago, Christchurch, Christchurch, New Zealand.

C.A. Billy, MD, MMed (ClinEpi), University of Sydney; R.T. Lim, B-BMED, University of Sydney; M. Ruospo, MscMed, Diaverum Medical Scientific Office and Amedeo Avogadro University of Eastern Piedmont; S.C. Palmer, MB ChB, PhD, Department of Medicine, University of Otago, Christchurch; G.F. Strippoli, MD, PhD, University of Sydney, Diaverum Medical Scientific Office, University of Bari, and Diaverum Academy.

Address correspondence to Prof. G.F. Strippoli, Department of Emergency and Organ Transplantation, University of Bari, Piazza Giulio Cesare, 70124 Bari, Italy.E-mail: gfmstrippoli@gmail.com

Accepted for publication June 8, 2017. years increased from 76,000 to 114,000 in 1990 to 2010 , causing gout to rank $173 \mathrm{rd}$ of 291 diseases $^{4,5}$. Clinical guidelines recommend nonsteroidal antiinflammatory drugs (NSAID) as first-line therapy to treat acute gout ${ }^{6}$. However, NSAID increase risks of gastrointestinal (GI) bleeding in the short term and excess cardiovascular adverse events (AE) in the longer term ${ }^{7,8}$. NSAID are contraindicated in patients with kidney or liver dysfunction, bleeding disorders, or heart failure, precluding the use of these drugs among patients who have higher risks of recurrent acute gout ${ }^{9}$. Corticosteroids, a potential first-line therapy to reduce joint inflammation in acute gout ${ }^{10,11,12,13}$, have fewer clinical contraindications and drug interactions, particularly for people with chronic kidney disease ${ }^{9,14}$. However, corticosteroids are prescribed less often compared to NSAID ${ }^{15}$.

Two systematic reviews have suggested that corticosteroids may have similar efficacy with fewer AE compared to NSAID for treating acute gout ${ }^{16,17}$. However, both reviews were potentially inconclusive because of the very limited

Personal non-commercial use only. The Journal of Rheumatology Copyright $($ C 2018. All rights reserved. 
number of trials available when they were conducted, as well as statistical between-trial heterogeneity found in the analyses. Recently, 3 additional randomized trials have been published $^{18,19,20}$, indicating that further data aggregation and synthesis may be timely to inform practice.

The aim of this systematic review with metaanalysis was to evaluate the benefits and harms of corticosteroids compared with NSAID for the treatment of acute gout.

\section{MATERIALS AND METHODS}

This systematic review with metaanalysis has been conducted and reported using the Preferred Reporting Items for Systematic reviews and Meta-Analyses (PRISMA) ${ }^{21}$. No ethics approval is required for this review, in accordance with the policy of our institution.

Data sources and searches. We searched MEDLINE (OvidSP 1946 to present), EMBASE (OvidSP 1974 to Week 32, 2016), and CENTRAL (The Cochrane Library 1948 to present) through August 9, 2016, without language restriction for trials that met the review eligibility criteria using a highly sensitive and specific search strategy developed by an experienced information specialist. We also searched trial registry platforms (International Standard Randomized Controlled Trial Number registry, World Health Organization International Clinical Trials Registry Platform registry, and ClinicalTrials.gov) for ongoing trials. Additionally, we hand-searched the reference lists of the eligible trials. The search strategy is reported in Appendix A (available with the online version of this article).

Study selection. We included randomized controlled trials (RCT) or quasiRCT comparing the benefits and harms of corticosteroid and NSAID therapy (oral or injectable) for treating acute gout in adults. Trials were considered without date or language restrictions. We included trials involving adult patients ( $>18 \mathrm{yrs}$ old), diagnosed with acute gout based on clinical criteria and/or presence of monosodium urate (MSU) crystals in the synovial fluid of affected joints, and who did not receive corticosteroid or NSAID within $24 \mathrm{~h}$ of disease onset before randomization. Trials that involved patients with crystal-induced arthritis other than gout were excluded. Trials reported in languages other than English were translated before assessment.

Data extraction. Two reviewers (CAB, RTL) independently screened the title and abstracts identified by electronic searching before retrieving the full-text articles of trials that were potentially eligible. The same reviewers independently extracted data using a specified data form. Data extraction included trial design, year of publication, country of trial, clinical setting, followup period, demographic characteristics, diagnostic methods for assessment of gout, intervention, and outcome measures. When a trial was published more than once, we included the English version of the trial (if the other publication was not in English) or the paper with the most completed data. Further information required from the original authors was requested by e-mail and any relevant information obtained was included in the review. Discrepancies between reviewers were resolved through consensus.

Risks of bias and evidence quality. Two reviewers (CAB, RTL) independently evaluated the risks of bias in included studies using the Cochrane assessment tool ${ }^{22}$. We considered the standard domains including sequence generation, allocation concealment, blinding of participants and investigators, blinding of outcome assessment, incomplete outcome data, and selective outcome reporting (per protocol or intention-to-treat analysis). The quality of evidence was evaluated using the Grading of Recommendation, Assessment, Development and Evaluation (GRADE) system ${ }^{23}$. Discrepancies between authors were resolved through discussion.

Outcomes. The primary efficacy outcome was pain score during followup (within 7 days and $\geq 7$ days) and the primary safety outcome was bleeding. Additional outcomes included joint swelling, erythema, tenderness, activity limitation, response to therapy, quality of life, time to resolution, amount of supplementary analgesics, and AE. We extracted data on outcome measures as reported by trial authors. The definitions of the clinical efficacy and safety outcomes included in metaanalyses are shown in Supplementary Table 1 (available with the online version of this article).

Statistical analysis. Treatment effects were summarized using randomeffects metaanalysis. For dichotomous outcomes, including response to therapy and $\mathrm{AE}$, results were expressed as relative risk (RR) and 95\% CI. For outcomes using continuous scales of measurement, including joint pain, swelling, erythema, tenderness, disability or restriction to joint activity, response to therapy, quality of life, time to resolution, and the number of supplementary analgesics, the results were expressed as a mean difference (MD) or standardized mean difference (SMD) if different scales were used together with the $95 \%$ CI. Missing SD were imputed by converting 95\% CI or $\mathrm{p}$ value using standard methods ${ }^{24}$.

The presence of statistical heterogeneity in treatment effects between studies was analyzed using the Cochran $\mathrm{Q}$ statistic, with a $\mathrm{p}$ value $<0.05$ indicating statistically significant heterogeneity in treatment effects between studies ${ }^{25}$. The $\mathrm{I}^{2}$ statistic was used to quantify the variation between trials due to heterogeneity, as an expression of the variation in treatment effects between studies that was not likely due to chance. We considered $\mathrm{I}^{2}$ values of $25 \%, 50 \%$, and $75 \%$ to indicate low, moderate, and high heterogeneity, respectively.

We planned subgroup analyses to evaluate sources of statistical heterogeneity based on timing of treatment (within 7 days of onset and $\geq 7$ days) on joint pain, swelling, erythema, tenderness, and disability or restriction of joint activity. Data observations were insufficient to conduct subgroup analyses for efficacy outcomes based on medication dose, route of administration, or concomitant urate-lowering therapy (ULT); subgroup analyses were only possible for adverse outcomes of therapy for these variables. All analyses were performed using Review Manager 5.3 (Cochrane Collaboration).

\section{RESULTS}

Study selection and baseline characteristics. Of 529 identified records, 6 trials involving 817 patients were eligible for inclusion in the review (Figure 1) $18,19,20,26,27,28$. Authors of 3 trials were contacted for additional details ${ }^{18,19,20}$. Authors of 1 trial responded, but did not report additional data. Of 6 trials, 5 were RCT $\mathrm{RT}^{18,19,20,27,28}$ and 1 was a quasi-RCT ${ }^{26}$. The mean study followup was 15 days (range, 4 to 30 days). Two trials recruited hospitalized patients ${ }^{18,19}$, 2 trials recruited patients visiting an emergency department $^{20,28}$, 1 trial recruited patients from outpatient clinics ${ }^{27}$, and in 1 trial the place of clinical presentation was not reported $^{26}$.

The characteristics of included trials are detailed in Table 1. The participants allocated to corticosteroids were between 44 years and 65.9 years on average and men were $70 \%$ to $100 \%$ of study participants. The participants allocated to NSAID were between 44.2 and 66.0 years on average and men were $79 \%$ to $100 \%$ of study participants.

In 4 trials, clinical criteria were used for the diagnosis of acute gout ${ }^{18,19,20,28}$, while in 2 trials, the diagnosis was based on the presence of intraarticular MSU crystals ${ }^{26,27}$. One trial compared corticosteroid therapy with selective and nonselective NSAID ${ }^{19}$, while the remainder compared corticosteroids with nonselective cyclooxygenase inhibitor NSAID $18,20,26,27,28$. Two trials prescribed additional nonrandomized analgesics to all participants every $6 \mathrm{~h}^{20}$ or $4 \mathrm{~h}^{28}$ as needed. One trial included additional analgesic therapy to

Personal non-commercial use only. The Journal of Rheumatology Copyright @ 2018 . All rights reserved. 


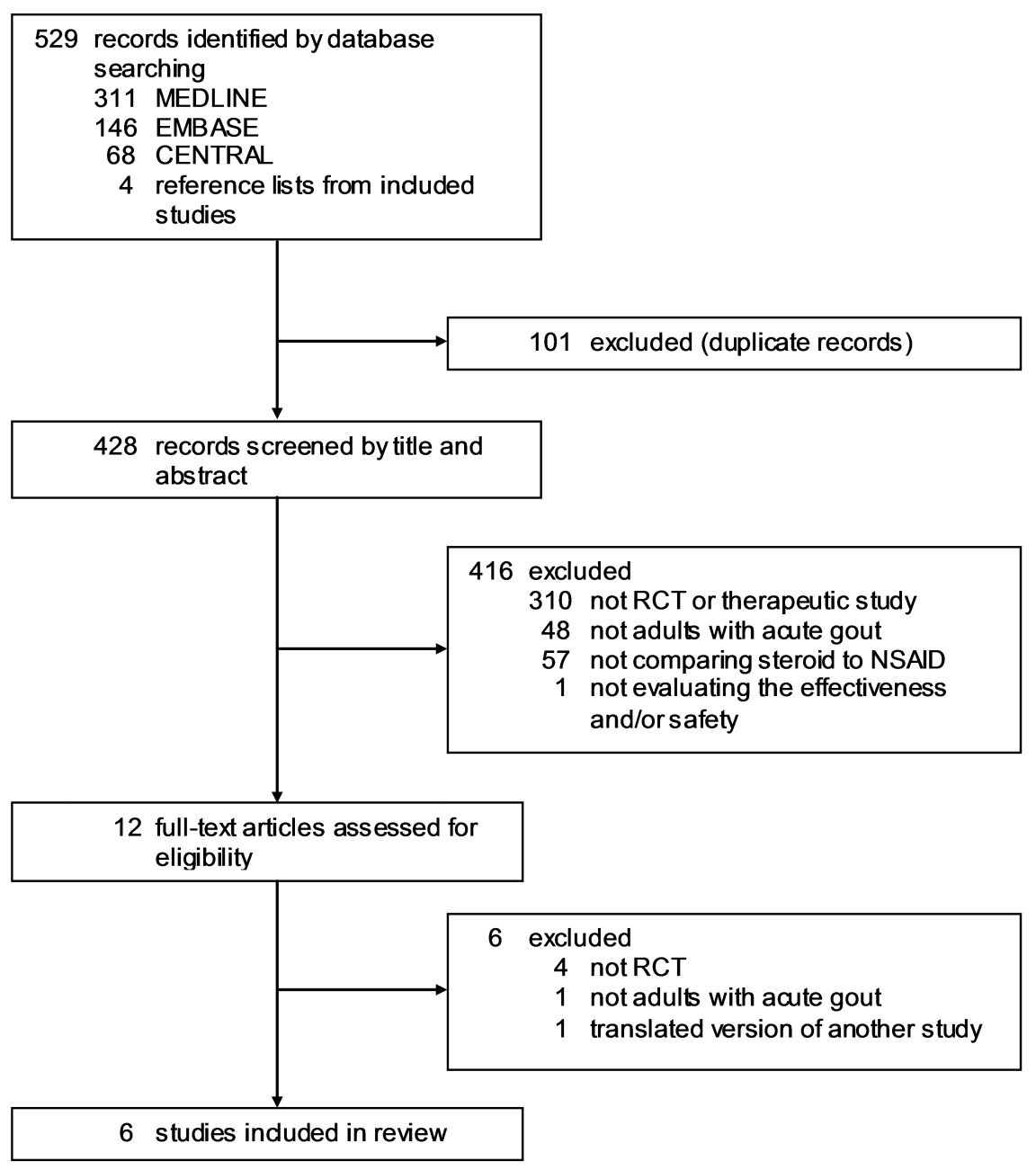

Figure 1. Flow chart showing the number of records retrieved and number of trials included in the review. RCT: randomized controlled trial; NSAID: nonsteroidal antiinflammatory drug.

participants allocated to corticosteroids if the participants experienced $<50 \%$ improvement 1 to 2 days after therapy ${ }^{26}$. Two trials allowed participants to continue taking ULT and other medications regularly ${ }^{19,26}$.

Risk of bias and evidence quality. Risks of bias in the included trials are shown in Supplementary Figure 1 (available with the online version of this article). Sequence generation was adequate in 4 of 6 trials $(67 \%)^{19,20,27,28}$ and unclear in 1 of 6 trials $(17 \%)^{18}$. Allocation concealment was adequate in 3 of 6 trials $(50 \%)^{19,20,28}$ and unclear in 3 of 6 trials $(50 \%)^{18,26,27}$. Three trials $(50 \%)$ were open-label ${ }^{18,19,26}$, while the other $3(50 \%)$ masked participants and investigators to treatment allocation ${ }^{20,27,28}$. Three trials (50\%) reported intention-to-treat analysis ${ }^{18,20,28}$. The number of patients lost to followup ranged from $0 \%$ to $26 \%$. Three trials (50\%) did not report all prespecified outcomes ${ }^{20,26,28}$. In accordance with GRADE criteria, the evidence quality was initially high based on the randomized study design. However, further downgrades for study limitations and imprecision resulted in low to moderate evidence quality (Table 2).

Pain. There was no significant difference in pain scores between corticosteroid and NSAID treatment within 7 days (2 RCT, 534 participants, SMD $-0.09,95 \%$ CI -0.26 to 0.08 ; moderate-quality evidence) ${ }^{20,27}$ and longterm (2 RCT, 506 patients, SMD $0.32,95 \%$ CI -0.27 to 0.92 ; low-quality evidence $)^{20,28}$. There was no evidence of statistical heterogeneity in treatment effects within 7 days $\left(\mathrm{p}=0.65, \mathrm{I}^{2}=0 \%\right)$, but heterogeneity was substantial between studies reporting treatment effects at $\geq 7$ days ( $\mathrm{p}=0.01, \mathrm{I}^{2}=85 \%$; Figure 2$)$.

Response to therapy. There was no evidence of different responses to therapy comparing corticosteroid and NSAID in the short term (2 RCT, 173 patients, RR 1.07, 95\% CI $0.80-1.44$; low-quality evidence) ${ }^{18,19}$ or long term in a single study ${ }^{18}$, with $95 \%$ CI consistent with both benefit and harm with therapy. Heterogeneity between treatment effects was moderate at 7 days $\left(\mathrm{p}=0.15, \mathrm{I}^{2}=53 \%\right)$ and not estimable for

Personal non-commercial use only. The Journal of Rheumatology Copyright $(\subset) 2018$. All rights reserved. 
Table 1. Characteristics of trials and participants.

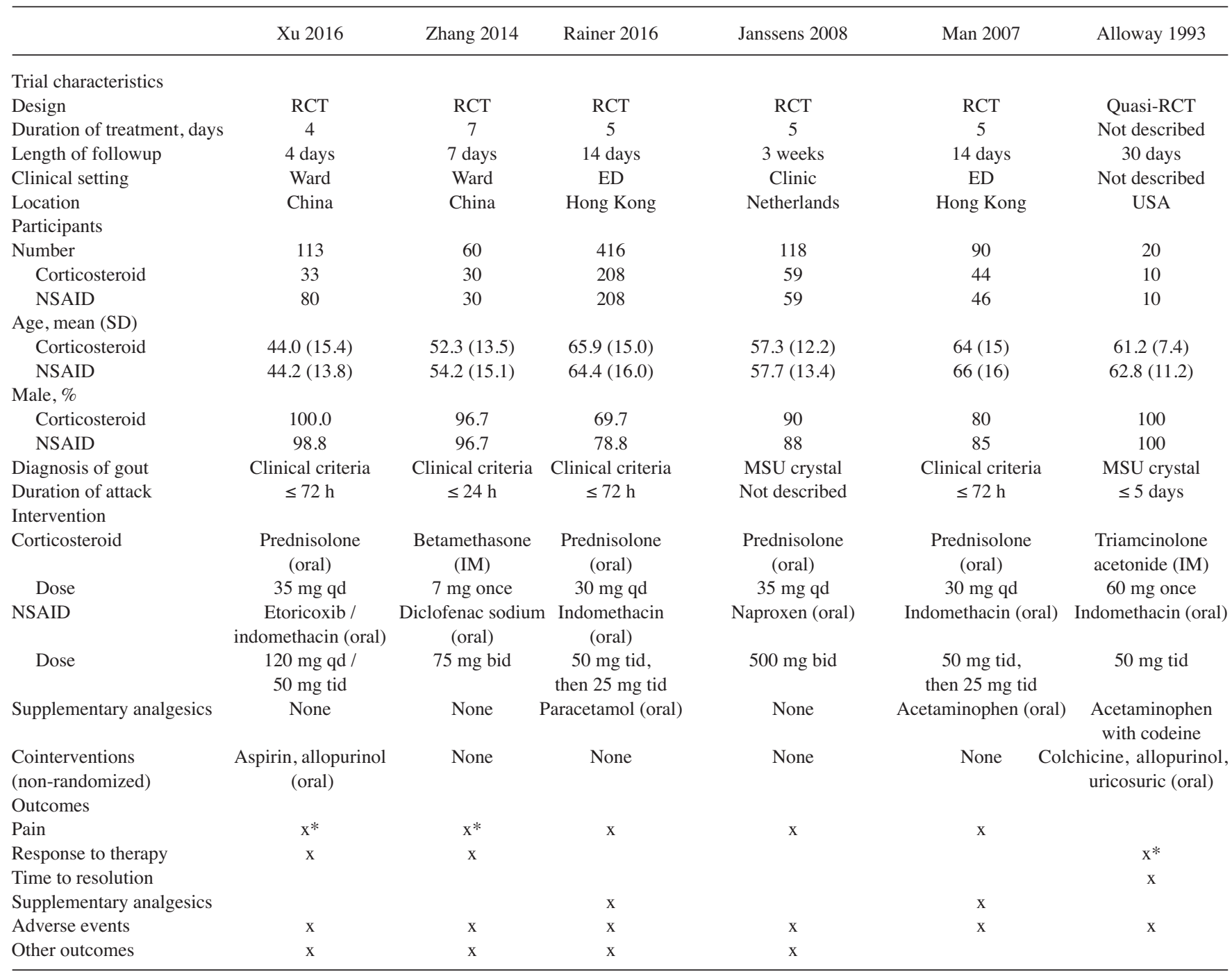

* Data could not be pooled in the metaanalysis. RCT: randomized controlled trials; NSAID: nonsteroidal antiinflammatory drugs; MSU: monosodium urate; IM: intramuscular; qd: once per day; bid: twice a day; tid: three times a day; ED: emergency department.

evaluation of longer term effects because there was only a single study reporting results (Figure 2).

Time to disease resolution. There was no evidence of different time to resolution of symptoms between corticosteroid and NSAID therapy in a single study ${ }^{26}$.

Number of supplementary analgesics. There was no significant difference in the number of supplementary analgesics used between corticosteroid and NSAID (2 RCT, 506 patients, MD 2.10 drugs, $95 \% \mathrm{CI}-1.01$ to 5.21$)^{20,28}$, with high-level statistical heterogeneity between trials $(\mathrm{p}=0.06$, $\mathrm{I}^{2}=72 \%$; Figure 2).

Analysis of $A E$. Corticosteroid therapy incurred a lower risk of indigestion ( $3 \mathrm{RCT}, 526$ patients, RR 0.50 , 95\% CI $0.27-0.92)^{20,26,28}$, nausea ( 3 RCT, 566 patients, RR 0.25 , $95 \%$ CI $0.11-0.54)^{18,20,28}$, and vomiting (2 RCT, 506 patients, RR $0.11,95 \%$ CI $0.02-0.56)^{20,28}$. NSAID therapy had a lower risk of rash (2 RCT, 506 patients, RR 4.62, 95\% CI 1.34-15.97) $)^{20,28}$.

There was evidence of statistically significant heterogeneity in summary effects of treatment for total AE ( $p$ for heterogeneity $=0.04, \mathrm{I}^{2}=56 \%$ ), gastric or abdominal pain ( $\mathrm{p}$ for heterogeneity $=0.05, \mathrm{I}^{2}=59 \%$ ), and withdrawal due to $\mathrm{AE}$ ( $\mathrm{p}$ for heterogeneity $=0.12, \mathrm{I}^{2}=58 \%$ ). Other $\mathrm{AE}$ reported in the included trials are detailed in Table 3.

Other outcomes. Other outcomes, including swelling, erythema, tenderness, and activity limitation reported in the included trials were summarized in Table 4. There was no trial that reported quality of life outcomes. Two trials reported that corticosteroid was significantly better in reducing swelling compared to NSAID ${ }^{18,19}$. One of 3 trials reported corticosteroid was significantly better in reducing tenderness 
Table 2. Summary of findings.

\begin{tabular}{|c|c|c|c|c|c|c|}
\hline Outcomes & $\begin{array}{l}\text { Illustrative Comp } \\
\text { Assumed Risk } \\
\text { NSAID }\end{array}$ & $\begin{array}{l}\text { rative Risks* }(95 \% \mathrm{CI}) \\
\text { Corresponding Risk } \\
\text { Corticosteroid }\end{array}$ & $\begin{array}{l}\text { Relative Effect } \\
\qquad(95 \% \mathrm{CI})\end{array}$ & $\begin{array}{l}\text { No. Participants } \\
\quad \text { (studies) }\end{array}$ & $\begin{array}{l}\text { Quality of the } \\
\text { Evidence } \\
\text { (GRADE)** }\end{array}$ & Comments \\
\hline $\begin{array}{l}\text { Pain }- \text { long term } \\
\text { ( } \geq 7 \text { days }) \text {, up to } 14 \text { days }\end{array}$ & \multicolumn{2}{|c|}{$\begin{array}{l}\text { The mean pain reduction in corticosteroid } \\
\text { group was } 0.32 \text { higher }(0.27 \text { lower to } \\
0.92 \text { higher) than in NSAID group }\end{array}$} & $\begin{array}{l}\text { SMD } 0.32 \\
(-0.27 \text { to } 0.92)\end{array}$ & $506(2)$ & Low & $\begin{array}{l}\text { Imprecision }(-1) \text {, } \\
\text { heterogeneity }(-1)\end{array}$ \\
\hline \multicolumn{2}{|c|}{$\begin{array}{l}\text { Response to therapy (physicians), } 850 \text { per } 1000 \\
\text { up to } 7 \text { days }\end{array}$} & $\begin{array}{l}43 \text { more per } 1000 \\
\text { (from } 43 \text { fewer } \\
\text { to } 144 \text { more) }\end{array}$ & RR $1.05(0.95-1.17)$ & $173(2)$ & Low & $\begin{array}{l}\text { Study limitation }(-1) \\
\text { imprecision }(-1)\end{array}$ \\
\hline GI bleeding, up to 14 days & 109 per 1000 & $\begin{array}{l}\text { Not estimable } \\
\text { (1 study only) }\end{array}$ & Not estimable & $90(1)$ & Not estimable & Single study only \\
\hline $\begin{array}{l}\text { Gastric or abdominal pain, } \\
\text { up to } 14 \text { days }\end{array}$ & 111 per 1000 & $\begin{array}{l}52 \text { fewer per } 1000 \\
\text { (from } 44 \text { more to } \\
\quad 88 \text { fewer) }\end{array}$ & RR $0.53(0.20-1.40)$ & $797(5)$ & Low & $\begin{array}{l}\text { Imprecision }(-1) \text {, } \\
\text { heterogeneity }(-1)\end{array}$ \\
\hline Hyperglycemia, up to 7 days & 0 per 1000 & $\begin{array}{l}\text { Not estimable } \\
\text { (1 study only) }\end{array}$ & Not estimable & $60(1)$ & Not estimable & Single study only \\
\hline
\end{tabular}

*The assumed risk is the median control group risk across studies. The corresponding risk (and its 95\% CI) is based on the assumed risk in the comparison group and the relative effect of the intervention (and its 95\% CI). **GRADE (Grading of Recommendation, Assessment, Development and Evaluation working group) grades of evidence: moderate quality - further research is likely to have an important effect on our confidence in the estimate of effect and may change the estimate; low quality - further research is very likely to have an important effect on our confidence in the estimate of effect and is likely to change the estimate. RR: risk ratio; NSAID: nonsteroidal antiinflammatory drugs; SMD: standardized mean difference; GI: gastrointestinal.

compared to NSAID ${ }^{18}$. Other trials reported that corticosteroid was equally effective as NSAID in reducing erythema and improving activity limitation ${ }^{19,20,27}$. The included studies did not report treatment effects on kidney function or injury; therefore, determining the different effects of NSAID and corticosteroids on renal outcomes was not possible.

Subgroup analyses. We did subgroup analyses for metaanalysis of AE in which at least 4 studies were included and there was evidence of statistical heterogeneity between studies. There was no evidence of different treatment effects based on steroid dose for the outcomes of abdominal pain [p (for subgroup difference) $=0.25, \mathrm{I}^{2}=25.9 \%$ ], total AE $\left(\mathrm{p}=0.96, \mathrm{I}^{2}=0 \%\right)$, or withdrawal due to $\mathrm{AE}(\mathrm{p}=0.13$, $\mathrm{I}^{2}=56 \%$ ). Subgroup analysis showed no statistical effect for different routes of administration in corticosteroid therapy (oral or intramuscular) on total $\mathrm{AE}\left(\mathrm{p}=0.42, \mathrm{I}^{2}=0 \%\right)$ and withdrawal due to AE (not estimable because of 0 events in intramuscular administered corticosteroid group). There was no evidence of different effects on total $\mathrm{AE}(\mathrm{p}=0.22$, $\left.\mathrm{I}^{2}=34 \%\right)$ or withdrawal from treatment $\left(\mathrm{p}=0.22, \mathrm{I}^{2}=34 \%\right)$ based on whether concomitant ULT was used.

\section{DISCUSSION}

In our systematic review comparing NSAID with corticosteroid therapy for treatment of acute gout, there was no evidence of different effects between treatment strategies for the management of pain, joint swelling, erythema, tenderness, or activity limitations among adults presenting with acute gout. There was no evidence that corticosteroids and NSAID had different responses to therapy, time to resolution, or requirement for additional analgesics. Corticosteroids were associated with lower risks of indigestion, nausea, and vomiting than NSAID, while NSAID were associated with lower risks of rash compared with corticosteroids. Treatment effects were uncertain owing to the small number of existing studies, and current RCT evidence remains insufficient to inform practice of the comparative superiority of any of these agents.

The results of this systematic review are concordant with those of 2 existing systematic reviews observing that corticosteroid and NSAID achieved similar pain control ${ }^{16,17}$. However, as with our current study, the results in those studies were imprecise as expected because of sparse data; in 1 review, pain management was reported in 2 studies involving 210 participants ${ }^{17}$, while a second review included 1 study with 90 participants ${ }^{16}$. As in our current study, these earlier reviews reported similarly on time to resolution, response therapy, and joint function with each therapy.

Our study adds a limited amount of additional precision, but also the investigation of a broader range of clinically relevant outcomes, as suggested by the Outcome Measures in Rheumatology (OMERACT) initiative, including swelling,

Personal non-commercial use only. The Journal of Rheumatology Copyright $\subset$ $\subset$ 2018. All rights reserved 
(A) Pain

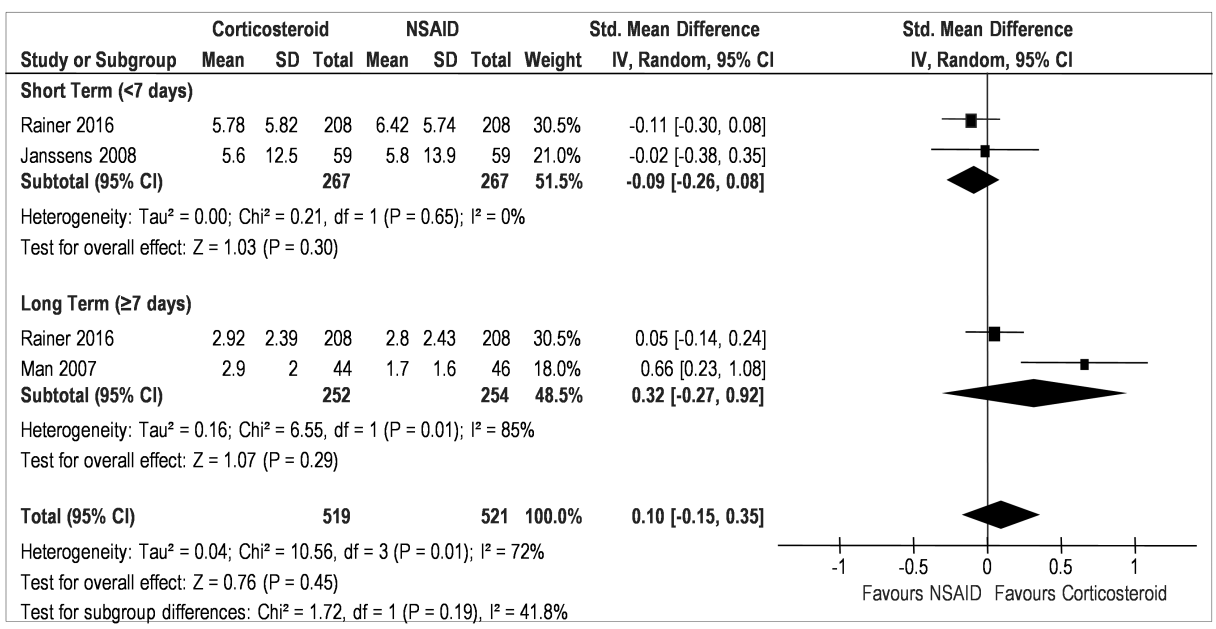

(B) Response to therapy

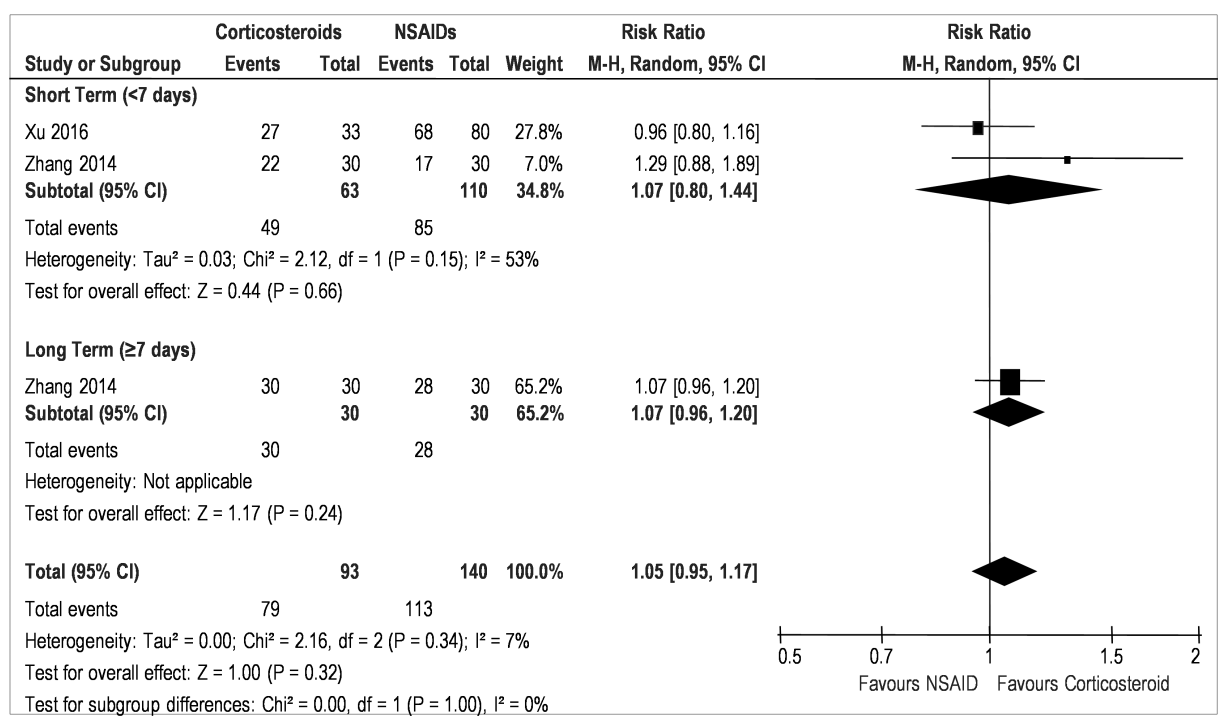

(C) Amount of supplementary analgesics

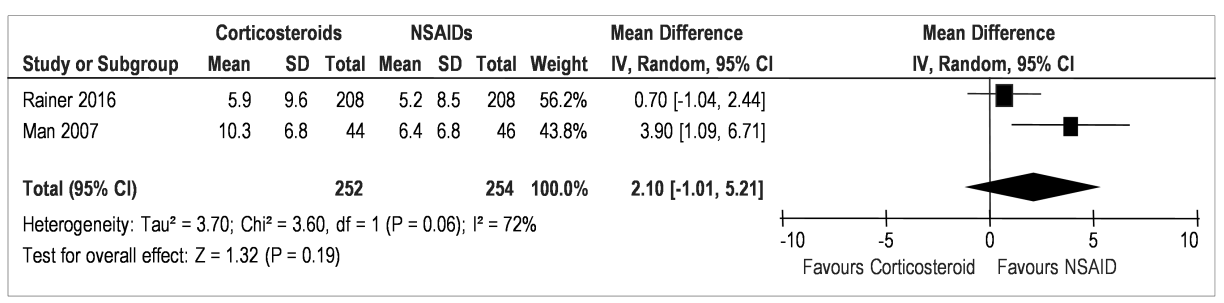

Figure 2. Effect of corticosteroids versus NSAID on (A) pain, (B) response to therapy, and (C) amount of supplementary analgesics. NSAID: nonsteroidal antiinflammatory drug.

erythema, and tenderness ${ }^{29}$. Moreover, the current review included more safety outcomes, such as GI events and hyperglycemia, which are associated with the use of NSAID and corticosteroids, respectively ${ }^{9}$.

This study did not show that NSAID incurred a higher risk of GI bleeding or cardiovascular AE, likely owing to the short-term nature of prescribing and small numbers of events. However, corticosteroids demonstrated similar efficacy to NSAID with lower risks of GI AE, particularly indigestion, nausea, and vomiting. Considering that many adults with acute gout are older or have medical comorbidity, and may be susceptible to NSAID gastropathy ${ }^{7}$, corticosteroids may

$$
\text { Personal non-commercial use only. The Journal of Rheumatology Copyright @ } 2018 \text {. All rights reserved. }
$$


Table 3. Adverse events (AE) of corticosteroid use compared to NSAID use in treatment of acute gout.

\begin{tabular}{|c|c|c|c|c|c|}
\hline \multirow[b]{2}{*}{ GI bleeding } & \multirow{2}{*}{$\begin{array}{c}\text { No. Studies } \\
1\end{array}$} & \multirow{2}{*}{$\begin{array}{c}\text { No. Participants } \\
90\end{array}$} & \multicolumn{2}{|c|}{ RR $(95 \% \mathrm{CI})$} & \multirow{2}{*}{$\frac{\text { Heterogeneity } \mathrm{I}^{2}(\%)}{\text { N/A }}$} \\
\hline & & & 0.09 & $(0.01-1.67)$ & \\
\hline Gastric or abdominal pain & 5 & 797 & 0.53 & $(0.20-1.40)$ & 59 \\
\hline Diarrhea & 2 & 208 & 0.22 & $(0.02-1.87)$ & 0 \\
\hline Flatulence & 1 & 60 & 0.20 & $(0.01-4.00)$ & N/A \\
\hline Nausea & 3 & 566 & 0.25 & $(0.11-0.54)^{\mathrm{c}}$ & 0 \\
\hline Dizziness or itchiness & 5 & 797 & 0.68 & $(0.44-1.05)$ & 0 \\
\hline Fatigue or drowsiness & 4 & 737 & 0.94 & $(0.61-1.43)$ & 0 \\
\hline Insomnia & 2 & 178 & 1.60 & $(0.20-12.77)$ & 0 \\
\hline Dry mouth & 3 & 619 & 1.32 & $(0.87-2.00)$ & 0 \\
\hline Rash & 2 & 506 & 4.62 & $(1.34-15.97)^{\mathrm{a}}$ & 0 \\
\hline Edema & 3 & 291 & 0.48 & $(0.09-2.57)$ & 0 \\
\hline Withdrawal due to $\mathrm{AE}$ & 6 & 825 & 0.44 & $(0.06-3.43)$ & 58 \\
\hline Recurrence & 4 & 341 & 0.86 & $(0.60-1.23)$ & 0 \\
\hline
\end{tabular}

${ }^{\mathrm{a}} \mathrm{p}<0.05 ;{ }^{\mathrm{b}} \mathrm{p}<0.01 ;{ }^{\mathrm{c}} \mathrm{p}<0.001 . \mathrm{I}^{2}$ values of $25 \%, 50 \%$, and $75 \%$ indicate low, moderate, and high heterogeneity, respectively. NSAID: nonsteroidal antiinflammatory drug; RR: risk ratio; N/A: not available; GI: gastrointestinal.

Table 4. Other outcomes comparing corticosteroid and NSAID for treating acute gout as reported in the included trials.

\begin{tabular}{|c|c|c|c|c|c|}
\hline Study & $\mathrm{N}$ & Intervention & $\begin{array}{c}\text { Mean } \pm \mathrm{SD} \\
\text { (corticosteroid group) } \\
\text { or percentages }\end{array}$ & $\begin{array}{c}\text { Mean } \pm \text { SD } \\
\text { (NSAID group) } \\
\text { or percentages }\end{array}$ & $\operatorname{MD}(95 \% \mathrm{CI})$ \\
\hline \multirow[t]{2}{*}{ Xu 2016} & 77 & Prednisolone vs etoricoxib & N/A & N/A & $0.21(-0.04 \text { to } 0.46)^{\mathrm{a}}$ \\
\hline & 69 & Prednisolone vs indomethacin & N/A & N/A & $0.33(0.07-0.58)^{\mathrm{b}}$ \\
\hline Zhang 2014 & 60 & Betamethasone vs diclofenac sodium & $100 \%$ to $77 \%$ to $3 \% \mathrm{c}$ & $100 \%$ to $93 \%$ to $10 \% \mathrm{c}$ & $\mathrm{N} / \mathrm{A}^{\mathrm{e}}$ \\
\hline Xu 2016 & 69 & Prednisolone vs indomethacin & N/A & N/A & $0.11(-0.12 \text { to } 0.34)^{\mathrm{a}}$ \\
\hline Rainer 2016 & 516 & Prednisolone vs indomethacin & $1.10 \pm 0.72$ & $1.15 \pm 0.73$ & $\mathrm{~N} / \mathrm{A}^{\mathrm{a}}$ \\
\hline \multicolumn{6}{|l|}{ Tenderness } \\
\hline \multirow[t]{2}{*}{ Xu 2016} & 77 & Prednisolone vs etoricoxib & N/A & N/A & $0.11(-0.08 \text { to } 0.31)^{\mathrm{a}}$ \\
\hline & 69 & Prednisolone vs indomethacin & $\mathrm{N} / \mathrm{A}$ & N/A & $0.13(-0.08 \text { to } 0.33)^{\mathrm{a}}$ \\
\hline Zhang 2014 & 60 & Betamethasone vs diclofenac sodium & $100 \%$ to $73 \%$ to $7 \% \mathrm{~d}$ & $100 \%$ to $93 \%$ to $13 \% \mathrm{~d}$ & $\mathrm{~N} / \mathrm{A}^{\mathrm{e}}$ \\
\hline \multirow[t]{2}{*}{ Janssens 2008} & 118 & Prednisolone vs naproxen & General: $42.1 \pm 29.6$ & General: $42.4 \pm 26.4$ & $0.3(-10.5 \text { to } 9.9)^{\mathrm{a}}$ \\
\hline & 109 & & Walking: $53.5 \pm 28.1$ & Walking: $54.4 \pm 22.3$ & $0.8(-10.5 \text { to } 8.8)^{\mathrm{a}}$ \\
\hline
\end{tabular}

${ }^{a} p$ value not significant. ${ }^{b} p<0.05 .{ }^{c}$ Percentage of patients that had swelling (palpable, visible, or bulging) at baseline, Day 3 , and Day $7 .{ }^{d}$ Percentage of patients that had tenderness on palpation or passive movement at baseline, Day 3, and Day $7 .{ }^{\mathrm{e}} \mathrm{p}<0.05$ at Day 3, but $\mathrm{p}$ value not significant at Day 7. NSAID: nonsteroidal antiinflammatory drugs; MD: mean difference; N/A: not applicable.

be preferred in treatment of acute gout for some patients based on lower treatment toxicity. Additionally, an economic analysis showed that corticosteroids were more cost-efficient than NSAID in managing acute gout ${ }^{30}$. Therefore, given low certainty in efficacy differences between treatments and potentially lower side effects with corticosteroids, corticosteroids might be considered the first therapy for acute gout.

The strengths of this review included a systematic literature search in electronic databases, trials registries, and hand-searching of reference lists, and included a broad range 
of clinically relevant outcomes as suggested by OMERACT for acute gout, i.e., pain, swelling, erythema, tenderness, activity limitation, patients' response to therapy, and quality of life ${ }^{29}$. The review was conducted by 2 independent investigators who identified eligible studies and extracted outcome data.

However, limitations in our study need to be considered when interpreting the results. The limitations of this review are largely based on the limitations in the primary evidence base on which the analyses have been conducted, including the number of available trials and the methodological reporting of the available studies. First, the relatively few available studies resulted in imprecise treatment estimates for many outcomes that included the possibilities of either benefit or harm. Moreover, the limited number of studies prevented subgroup analysis to analyze the effect of medication dose or route of administration, and concomitant use of ULT on treatment efficacy. Second, many trials had high risks of bias, or methodological reporting was insufficient to assess risks of bias for some methodological domains that were considered. Of the 6 trials, none reported methods considered to give a low risk of bias across all domains. Therefore, additional high-quality trials may offer different treatment estimates and increase our confidence in the comparative effects of corticosteroids and NSAID for acute gout. Third, 4 of 6 studies diagnosed acute gout using clinical criteria instead of confirming the presence of MSU crystals within joint spaces. Hence, there was a possibility that participants with an alternative diagnosis for their symptoms might have been included in the studies, and they may have had a different response to therapy. Nevertheless, the diagnosis of acute gout was mostly made using clinical criteria and similar to common clinical practice, increasing the generalizability of the trial findings. Fourth, the included studies did not report treatment effects on kidney function or injury, and therefore an analysis of the comparative effects of NSAID and corticosteroids on renal outcomes was not possible. Similarly, there was relatively sparse information to inform treatment effects on patient-level outcomes including absenteeism and health-related quality of life, and there were relatively short periods of followup. Finally, our review did not include evaluation of the benefits and harms of colchicine because RCT assessing colchicine were not available. Future trials should report recommended clinical outcomes, effect on kidney function or injury, include longer-term followup to assess treatment benefits and harms, and include colchicine in comparison to NSAID and/or corticosteroid-based therapy. Based on the patient and economic burden of acute gout and the potential toxicities of therapy, these large trials might be reasonably considered high priorities.

There is insufficient information to determine the comparative efficacy of corticosteroids and NSAID to treat acute gout, while corticosteroids appear to have a more favorable safety profile for selected AE reported by available RCT.

\section{ACKNOWLEDGMENT}

We thank Dr. Margaret Merlyn Tjiang, who shared her knowledge on recent issues in internal medicine, helping us decide on the topic for this review.

\section{ONLINE SUPPLEMENT}

Supplementary material accompanies the online version of this article.

\section{REFERENCES}

1. Kuo CF, Grainge MJ, Mallen C, Zhang W, Doherty M. Rising burden of gout in the UK but continuing suboptimal management: a nationwide population study. Ann Rheum Dis 2015;74:661-7.

2. Wallace KL, Riedel AA, Joseph-Ridge N, Wortmann R. Increasing prevalence of gout and hyperuricemia over 10 years among older adults in a managed care population. J Rheumatol 2004;31:1582-7.

3. Wertheimer A, Morlock R, Becker MA. A revised estimate of the burden of illness of gout. Curr Ther Res Clin Exp 2013;75:1-4.

4. Murray CJ, Vos T, Lozano R, Naghavi M, Flaxman AD, Michaud C, et al. Disability-adjusted life years (DALYs) for 291 diseases and injuries in 21 regions, 1990-2010: a systematic analysis for the Global Burden of Disease Study 2010. Lancet 2012;380:2197-223.

5. Smith E, Hoy D, Cross M, Merriman TR, Vos T, Buchbinder R, et al. The global burden of gout: estimates from the Global Burden of Disease 2010 study. Ann Rheum Dis 2014;73:1470-6.

6. Zhang W, Doherty M, Bardin T, Pascual E, Barskova V, Conaghan $P$, et al. EULAR evidence based recommendations for gout. Part II: Management. Report of a task force of the EULAR Standing Committee for International Clinical Studies Including Therapeutics (ESCISIT). Ann Rheum Dis 2006;65:1312-24.

7. Hawkey CJ. Nonsteroidal anti-inflammatory drug gastropathy. Gastroenterology 2000;119:521-35.

8. Graham DJ, Campen D, Hui R, Spence M, Cheetham C, Levy G, et al. Risk of acute myocardial infarction and sudden cardiac death in patients treated with cyclo-oxygenase 2 selective and non-selective non-steroidal anti-inflammatory drugs: nested case-control study. Lancet 2005;365:475-81.

9. Neogi T. Clinical practice. Gout. N Engl J Med 2011;364:443-52.

10. Graf SW, Whittle SL, Wechalekar MD, Moi JH, Barrett C, Hill CL, et al. Australian and New Zealand recommendations for the diagnosis and management of gout: integrating systematic literature review and expert opinion in the $3 \mathrm{e}$ Initiative. Int $\mathrm{J}$ Rheum Dis 2015;18:341-51.

11. Khanna D, Khanna PP, Fitzgerald JD, Singh MK, Bae S, Neogi T, et al. 2012 American College of Rheumatology guidelines for management of gout. Part 2: therapy and antiinflammatory prophylaxis of acute gouty arthritis. Arthritis Care Res 2012;64:1447-61.

12. Richette P, Doherty M, Pascual E, Barskova V, Becce F, Castañeda-Sanabria J, et al. 2016 updated EULAR evidence-based recommendations for the management of gout. Ann Rheum Dis 2017;76:29-42.

13. Qaseem A, Harris RP, Forciea MA. Management of acute and recurrent gout: a clinical practice guideline from the American College of Physicians. Ann Intern Med 2017;166:58-68.

14. Terkeltaub RA. Clinical practice. Gout. N Engl J Med 2003;349:1647-55.

15. Riedel AA, Nelson M, Wallace K, Joseph-Ridge N, Cleary M, Fam AG. Prevalence of comorbid conditions and prescription medication use among patients with gout and hyperuricemia in a managed care setting. J Clin Rheumatol 2004;10:308-14.

16. Janssens HJ, Lucassen PL, Van de Laar FA, Janssen M, Van de Lisdonk EH. Systemic corticosteroids for acute gout. Cochrane Database Syst Rev 2008;CD005521.

17. van Durme CM, Wechalekar MD, Buchbinder R, Schlesinger N, van der Heijde D, Landewé RB. Non-steroidal anti-inflammatory drugs for acute gout. Cochrane Database Syst Rev 2014;CD010120.

Personal non-commercial use only. The Journal of Rheumatology Copyright (C) 2018. All rights reserved. 
18. Zhang YK, Yang H, Zhang JY, Song LJ, Fan YC. Comparison of intramuscular compound betamethasone and oral diclofenac sodium in the treatment of acute attacks of gout. Int J Clin Pract 2014;68:633-8

19. Xu L, Liu S, Guan M, Xue Y. Comparison of prednisolone, etoricoxib, and indomethacin in treatment of acute gouty arthritis: an open-label, randomized, controlled trial. Med Sci Monit 2016;22:810-7.

20. Rainer TH, Cheng CH, Janssens HJ, Man CY, Tam LS, Choi YF, et al. Oral prednisolone in the treatment of acute gout: a pragmatic, multicenter, double-blind, randomized trial. Ann Intern Med 2016;164:464-71.

21. Moher D, Liberati A, Tetzlaff J, Altman DG. Preferred reporting items for systematic reviews and meta-analyses: the PRISMA statement. PLoS Med 2009;6:e1000097.

22. Higgins JP, Altman DG, Gotzsche PC, Juni P, Moher D, Oxman AD, et al. The Cochrane Collaboration's tool for assessing risk of bias in randomised trials. BMJ 2011;343:d5928.

23. Guyatt GH, Oxman AD, Vist GE, Kunz R, Falck-Ytter Y, Alonso-Coello P, et al. GRADE: an emerging consensus on rating quality of evidence and strength of recommendations. BMJ 2008;336:924-6.

24. Higgins JP, Deeks JJ, editors. Chapter 7: Selecting studies and collecting data. In: Higgins JPT, Green S, editors. Cochrane Handbook for Systematic Reviews of Interventions Version 5.1.0 [updated March 2011]. The Cochrane Collaboration, 2011. [Internet. Accessed June 21, 2017.] Available from: http://handbook.cochrane.org

25. Higgins JP, Thompson SG, Deeks JJ, Altman DG. Measuring inconsistency in meta-analyses. BMJ 2003;327:557-60.

26. Alloway JA, Moriarty MJ, Hoogland YT, Nashel DJ. Comparison of triamcinolone acetonide with indomethacin in the treatment of acute gouty arthritis. J Rheumatol 1993;20:111-3.

27. Janssens HJ, Janssen M, van de Lisdonk EH, van Riel PL, van Weel C. Use of oral prednisolone or naproxen for the treatment of gout arthritis: a double-blind, randomised equivalence trial. Lancet 2008;371:1854-60.

28. Man CY, Cheung IT, Cameron PA, Rainer TH. Comparison of oral prednisolone/paracetamol and oral indomethacin/paracetamol combination therapy in the treatment of acute goutlike arthritis: a double-blind, randomized, controlled trial. Ann Emerg Med 2007;49:670-7.

29. Singh JA, Taylor WJ, Dalbeth N, Simon LS, Sundy J, Grainger R, et al. OMERACT endorsement of measures of outcome for studies of acute gout. J Rheumatol 2014;41:569-73.

30. Cattermole GN, Man CY, Cheng CH, Graham CA, Rainer TH. Oral prednisolone is more cost-effective than oral indomethacin for treating patients with acute gout-like arthritis. Eur J Emerg Med 2009;16:261-6. 